\title{
LA MEDIA PRESCRIPCIÓN FRENTE AL DELITO DE DESAPARICIÓN FORZADA DE PERSONAS. ¿INCUMPLIMIENTO DE LA NORMATIVA INTERNACIONAL EN MATERIA DE CRÍMENES DE LESA HUMANIDAD? \\ Isabel González Ramírez, Samuel Malamud Herrera, María Soledad Fuentealba Martínez e Florencio Pardo Montenegro
}

HALF-LAPSING PRESCRIPTION FOR THE CRIME OF ENFORCED DISAPPEARANCE. BREACH OF INTERNATIONAL LAW REGARDING CRIMES AGAINST HUMANITY?

\section{RESUMO}

EL PRESENTE TRABAJO SE PRESENTA COMO UN ESTUDIO DEL TRATAMIENTO DE LA MEDIA PRESCRIPCIÓN APLICADA A LOS CRIIMENES DE DESAPARICIÓN FORZADA DE PERSONAS. LOS AUTORES ABORDAN LA PROBLEMÁTICA DESDE UNA PERSPECTIVA JURÍDICA E HISTÓRICA. EXPONIENDO CÓMO EL SISTEMA CHILENO EN CUANTO A LA MEDIA PRESCRIPCIÓN NO SE ENCUENTRA EN ARMONÍA CON LA LEGISLACIÓN INTERNACIONAL, EN ESPECIAL CON LAS DISPOSICIONES DE LOS TRATADOS INTERNACIONALES RATIFICADOS Y VIGENTES EN CHILE. CENTRANDO ESPECIALMENTE DICHO ANÁLISIS EN LA LÍNEA EVOLUTIVA JURISPRUDENCIAL DEL TRATAMIENTO DEL PROBLEMA POR PARTE DE LOS TRIBUNALES CHILENOS, INCLUYENDO DENTRO DE ESTE ANÁLISIS JURISPRUDENCIAL UN RECIENTE FALLO QUE PARECE CAMBIAR LA LÍNEA INTERPRETATIVA SUSTENTADA CON ANTERIORIDAD.

\section{PALAVRAS-CHAVE}

MEDIA PRESCRIPCIÓN; DESAPARICIÓN FORZADA; CRÍMENES DE LESA HUMANIDAD; IMPUNIDAD; IMPRESCRIPTIBILIDAD.

\section{ABSTRACT}

THIS PAPER IS PRESENTED AS A STUDY OF THE HALF-LAPSING PRESCRIPTION TREATMENT APPLIED TO THE CRIME OF ENFORCED DISAPPEARANCE. THE AUTHORS ADDRESS THE ISSUE FROM A LEGAL AND HISTORICAL PERSPECTIVE. EXPLAINING HOW THE CHILEAN SYSTEM IN TERMS OF THE HALF-LAPSING PRESCRIPTION IS NOT IN HARMONY WITH INTERNATIONAL LAW, IN PARTICULAR WITH THE PROVISIONS OF INTERNATIONAL TREATIES RATIFIED AND IN FORCE IN CHILE. FOCUSING ESPECIALLY THE ANALYSIS OF THE EVOLUTIONARY JURISPRUDENTIAL TREATMENT OF THE PROBLEM BY THE CHILEAN COURTS, INCLUDING IN THIS JURISPRUDENTIAL ANALYSIS A RECENT RULING THAT APPEARS TO CHANGE THE INTERPRETATIVE COURSE SUPPORTED PREVIOUSLY.

\section{KEYWORDS}

HALF LAPSING PRESCRIPTION; ENFORCED DISAPPEARANCE; CRIMES AGAINST HUMANITY; IMPUNITY; IMPRESCRIPTIBILITY.

\section{INTRODUCCIÓN}

Sin duda uno de los hitos que marcaron con tinta indeleble el pasado siglo fue el derrocamiento del gobierno del ex presidente socialista Salvador Allende, a través de un golpe militar que se sostuvo por 17 años y que dejo profundas secuelas y resquemores.

Los efectos colaterales de este hecho puntual y del desarrollo de un gobierno de facto que vulneró sistemáticamente los derechos humanos de miles de personas pueden analizarse desde distintas perspectivas y pueden perseguir distintos objetos. 
A grandes rasgos, podemos sostener que constituye un punto de interés la explicación causal y los efectos que podría haber causado el rompimiento institucional de la democracia, el hecho preciso de poner fin a un gobierno legítimamente electo, a través de un operativo militar y político bajo empleo de la fuerza.

Otro punto de interés es el que representa la prolongación, durante 17 años, de un gobierno de facto, caracterizado por la clausura del Congreso; la declaración de un estado de sitio, con la consiguiente suspensión de las garantías individuales; la prohibición de la vida política, de las actividades sindicales; la disolución del Tribunal Constitucional, la censura a prensa radio y televisión; la intervención de universidades y colegios (CORREA, 2001, 280 y ss.); y en donde la violación sistemática de derechos humanos constituyó una práctica sistemática y estratégica para la eliminación del enemigo político. ${ }^{1}$

Estos dos puntos de interés, brevemente anunciados, han sido abordados desde la óptica de distintas disciplinas, si bien cada cierto tiempo existen nuevos aportes y perspectivas, parece que no exigen una imperiosa necesidad de encontrar consensos, puesto que el avance, ha sido considerable.

Contrapuesto a lo anterior, un tercer aspecto de interés, que parece no haber sido suficientemente analizado, es la forma en que la judicatura ha afrontado los hechos ocurridos en este trágico período de nuestra historia. Especialmente en lo referido a la forma en que los procesos judiciales han dado respuesta a las necesidades de verdad, justicia y reparación, que exige la comunidad internacional, bajo el entendido que estos crímenes afectan a la humanidad toda.

Se plantea entonces el problema de determinar si los fallos emanados de nuestro más alto tribunal, respecto a casos de desaparición forzada de personas, ocurridos durante la dictadura militar, cumplen con los estándares establecidos por la comunidad internacional.

Frente a tal interrogante, sostenemos inicialmente que la línea jurisprudencial en esta materia se ha dividido, a grandes rasgos, en dos etapas: la primera que transcurre desde la transición a la democracia (1990) hasta el año 2006, período caracterizado por una total impunidad; y un segundo período que corre desde 2007 hasta nuestros días, en la cual si bien varios agentes del régimen militar son condenados, a la vez sus penas son atenuadas considerablemente por la institución de la media prescripción, de modo que cumplirían sus penas en libertad.

Bajo esa división temporal, el estudio aventura la hipótesis que la aplicación de la media prescripción o prescripción gradual regulada en el artículo 103. ${ }^{\circ}$ del Código Penal de Chile, en casos de delitos contra lesa humanidad, atenta entre otros contra el principio de imprescriptibilidad y proporcionalidad, contemplado en los tratados internacionales de derechos humanos ratificados y vigente en el país, y que no se condice con la lucha contra la impunidad, buscada en estos casos por la comunidad internacional. 
De esa forma, el presente trabajo tiene por objeto analizar desde una perspectiva histórica y principalmente jurídica, la atenuante de la media prescripción aplicada al delito de desaparición forzada de personas, en el sistema chileno.

Para el logro del objetivo antes descrito se revisará en qué consiste y cuál es la gravedad del delito de desaparición forzada de personas, el trato que se le ha dado a este delito en la legislación internacional y nacional y la historia de la aplicación de la institución de la prescripción y la media prescripción al delito de desaparición forzada de personas en Chile.

Antes de comenzar cualquier análisis, cabe tener presente que en Chile los delitos de desaparición forzada de personas, cometidos durante el régimen militar, han debido formalizarse como delitos de secuestro agravado, para respetar el principio de legalidad, dado que la normativa que los tipifica como detención ilegal y arbitraria, no estaba vigente en la época de su comisión. A través de la figura penal de secuestro agravado, han sido procesadas numerosas personas a partir de los años de los 90, sin embargo la variante jurisprudencia, más allá de reconocer la efectividad de tales hechos y de determinar quiénes fueron culpables de estos, ha recorrido un lamentable derrotero en el cual se partió por negar la imprescriptibilidad de los delitos cometidos durante el régimen militar, por conceder amnistías y más recientemente entregar beneficios de libertad vigilada a los condenados, amparados en la significante atenuación de la pena que permite la institución de la media prescripción o prescripción gradual de la pena, todo lo cual ha incidido en que exista cierto sentimiento de impunidad que dificulta el avanzar en pos de un proceso nacional de verdad, justicia y reparación.

Se expone en el trabajo que a partir de una serie de fallos dictados desde mediados del año 2007, la jurisprudencia de forma mayoritaria ha concedido el beneficio de la media prescripción a sus autores, lo que les ha permitido cumplir la pena en libertad, basándose en que la prohibición de aplicar la prescripción de la acción penal - cuyo efecto sería la extinción de la responsabilidad penal_ _ derivada de los compromisos internacionales asumidos por Chile, no implica la imposibilidad de aplicar la atenuante de media prescripción —que produce una atenuación de la pena-, dado que dichos compromisos no se refieren a ella.

Contrario a esto, los autores exponen una serie de argumentos en base a los cuales intentan demostrar que la prescripción de la acción penal, como la media prescripción, son instituciones que comparten más similitudes que diferencias, siendo la base de ambas el transcurso del tiempo y recayendo sus efectos sobre la pena a imponer, impidiéndola una y atenuándola la otra.

Seguido se analiza un reciente fallo de la Corte Suprema, del año 2012, el cual al desarrollar razones para no conceder la media prescripción plantea la posibilidad de un cambio de paradigma al respecto. 


\section{LA DESAPARICIÓN FORZADA DE PERSONAS. AProXimACión}

El delito de desaparición forzada de personas consiste en la aprehensión, detención o mantenimiento de una detención previa, o el secuestro de personas por funcionarios del Estado o de una organización política, o bien con su apoyo o aquiescencia, seguida de la negativa a reconocer o informar sobre la privación de libertad o dar información sobre la suerte o paradero de esas personas, con la intención de dejarlas fuera del amparo de la ley por un período prolongado (GIL GIL, 2007, p. 155).

Tal crimen se define en el artículo $2 .^{\circ}$ de la Convención Interamericana sobre desaparición forzada de personas de la Organización de los Estados Americanos, de la siguiente manera:

Para los efectos de la presente Convención, se considera desaparición forzada la privación de la libertad a una o más personas, cualquiera que fuere su forma, cometida por agentes del Estado o por personas o grupos de personas que actúen con la autorización, el apoyo o la aquiescencia del Estado, seguida de la falta de información o de la negativa a reconocer dicha privación de libertad o de informar sobre el paradero de la persona, con lo cual se impide el ejercicio de los recursos legales y de las garantías procesales pertinentes.

La desaparición forzada de personas, como practica represiva y sistemática, comienza a gestarse a partir de la segunda guerra mundial, identificando algunos autores su origen en la orden militar balance del terror surgida bajo la ocupación nazi de algunos países europeos (PADILLA, 2010, p. 39).

Lo fundamental en este delito radica en que los actos materiales que constituyen el delito, aun cuando la detención que en determinadas circunstancias puede incluso comenzar por ser legal, han de realizarse a nombre o con la autorización o apoyo del Estado, o de la organización política, en su caso.

En este delito, la intención de dejar a la víctima fuera del amparo de la ley debe concurrir con las conductas materiales de detención o de ocultación de la misma o de su paradero, pero si la víctima ha muerto, no es exigible que la ocultación de este dato se haga para privarla del amparo de la ley, puesto que esto ya no sería posible.

El bien jurídico que protege este delito es fundamentalmente la libertad de la persona para trasladarse de un lugar a otro o de situarse por sí mismo en el espacio. Entendiendo por libertad la capacidad del ser humano de fijar por sí mismo su situación en el espacio físico.

Si bien, lo anterior es cierto — y en cierta medida evidente — la amplia aplicación que estos delitos tuvieron en el contexto de dictaduras militares y gobiernos de facto en Latinoamérica durante las últimas tres décadas del siglo pasado (AMBOS; BÖHM, 2009, p. 199 y ss.), fuerza a analizar el desvalor de tales conductas y su lesividad, de manera más reflexiva. En ese sentido, Juan Bustos señala que lo que se estaría 
afectando en tales delitos, sería "la identidad como persona del sujeto pasivo", ya que se le estaría negando a través de ellos "una multiplicidad de actos en la vida jurídico-social, que aparecen negados con el desaparecimiento, desde los más simples y personales, hasta el de ser reconocida su muerte; en definitiva el derecho reconocido a mantener su identidad de persona humana tanto en la vida como en la muerte, cuestión fundamental en la historia del hombre y de la humanidad y que es lo que ha determinado su acervo y evolución histórica, cultural y ética” (BUSTOS RAMÍREZ, 1986, p. 186).

También entiende Ramón Ragués, que cuando al ser funcionarios del Estado quienes cometen estos delitos existiría una afectación que excedería la simple limitación de la esfera de libertad individual. Señala al respecto el autor:

Desde el punto de vista de la víctima la privación de libertad supone, de entrada, un ataque contra su libertad ambulatoria. Este primer aspecto explica ya por sí solo una parte sustancial del daño que causa este delito, al que se añade una importante afectación a la seguridad de la misma víctima, quien no solo ve restringida su capacidad de movimientos, sino que, por lo general, se verá obligada a vivir la detención en una situación de grave incertidumbre sobre cuál será su destino final. A ello se suma el daño que con la misma privación y la posterior desaparición se causa a las personas del entorno del sujeto pasivo, que se ven obligadas a vivir inicialmente en la incertidumbre sobre el bienestar de su ser querido y, a medida que van transcurriendo los años, a tener que soportar un estado de resignada duda sobre lo que pueda haberle sucedido. (RAGUÉS I VALLÉS, 2010, p. 52 y ss.)

Sumado a lo anterior, que la mencionada figura penal se trate de un delito especial propio, en la que se requiere una cualidad personal de su sujeto activo, cual es el ser un funcionario público o bien actuar amparado o bajo el reguardo del Estado, implica además la afectación de otro bien jurídico distinto a la libertad, que es la correcta administración pública (RAFECAS, 2010, p. 73).

Lo expuesto permite entender la hondura y complejidad que implica enfrentarse a tal delito, situación que ha planteado la preocupación de la comunidad internacional, propiciándose la comprensión de tal delito, como un de lesa humanidad; entendiendo el Estatuto de Roma, que cuando tales conductas "se cometan como parte de un ataque generalizado y sistemático contra una población civil”, constituyen un delito contra la humanidad toda. ${ }^{2}$

Adicionalmente, al estar involucrados funcionarios estatales en su comisión, se daría cabida a un principio que permitiría afirmar la dimensión internacional de éstas figuras, cual es que el Estado en que se ha cometido el delito no tenga interés ni ofrezca las garantías de persecución (RAGUÉS, 2010, p. 54). 
Por otro lado, este delito corresponde a los llamados delitos de resultado toda vez que se consuman una vez que el actor realiza los actos ejecutivos y existe efectiva privación de libertad de una persona, siendo esta privación de carácter permanente, ya que formal y materialmente para que el delito se consume se requieren una mínima continuidad temporal en la privación ilegal de libertad, para que cumpla con el principio de lesividad (RAFECAS, 2010, p. 313).

En todo caso el delito exige que el autor o autores hayan tenido la intención de dejar a la persona o personas fuera del amparo de la ley por un período prolongado, pero no durante todo el tiempo que dura la desaparición. Porque probablemente esa intención concurrirá o se transformará en la de no ser descubierto. La doctrina ha interpretado éste como un delito permanente, cuya realización se perpetúa hasta que aparece la víctima.

Por otra parte, al tratarse de delitos que afectan bienes personales, la pluralidad de las víctimas hace múltiples estos delitos por lo que no es un delito denominado como delito de masas. ${ }^{3}$

El tipo subjetivo de este delito exige el dolo, aunque sea eventual, el que comprende el conocer y querer no solo la detención sino también la negativa a informar, el conocimiento de que la conducta se enmarca en un ataque general o sistemático y la intención de marginar a la persona del amparo de la ley por un período prolongado, de manera que la privación de libertad fuera el único propósito de la acción. La posibilidad de la culpa queda descartada.

El tratamiento legal de este delito en Chile, cumple solo medianamente, con los estándares internacionales exigidos, dado que sin perjuicio de que actualmente no hay impedimentos jurídicos penales, ni constitucionales algunos para su imputación por la judicatura, puesto que el año 2010 a través del Decreto supremo n. 12 se promulga la aprobación de la Convención Interamericana sobre desaparición forzada de personas de la Organización de los Estados Americanos. Lo que parece especialmente grave es que no considerarían los delitos cometidos antes de la vigencia de esta convención, especialmente en el período del régimen militar, época en que se cometieron masivamente tales hechos, porque no existía en tal fecha normativa vigente al respecto y conforme al principio de legalidad penal, consagrado constitucional y legalmente (artículos 19. n. $3 .^{\circ}$ de la Constitución Política y $18 .^{\circ}$ del Código Penal), las leyes penales no pueden ser aplicadas con efecto retroactivo, viéndose obligados los tribunales a juzgar las desapariciones forzadas cometidas en esa época como un delito genérico de secuestro agravado.

Es importante tener en cuenta que estos delitos son una manifestación de las prácticas violentas propias de los regímenes autoritarios, que sin perjuicio de ser hoy ampliamente rechazada por los sistemas democráticos, aún persisten debido a la resistencia a abandonar estas ideologías y métodos por parte de las instituciones ligadas a la defensa y seguridad del Estado, las que promueven tendencias a ampliar el poder punitivo del 
Derecho Penal, legitimados hoy normativamente, por doctrinas tales como la del Derecho Penal del Enemigo, promovida por Gunther Jakobs (RAFECAS, 2010, p. 8).

Es así como esta tendencia que se manifestó en forma desmedida en Chile especialmente durante la primera década del régimen militar del gobierno de Augusto Pinochet Ugarte, que tuvo lugar entre los años 1973 al 1990, proviene de doctrinas propias del punitivismo, expansión del Derecho Penal, Derecho Penal de Autor, Derecho Penal simbólico y del enemigo, las que según Bergalli (2003, p. 36), tienen su origen en las conmociones que afectaron a la sociedad y al Estado liberal europeos, en fines del siglo XIX, las que anunciaron los conflictos y cambios que se iban a producir a comienzos del siglo XX, con los procesos de unidad nacional, en la primera guerra mundial (19141918), donde Europa se enfrascó en un afán expansionista, de totalitarismo, y del holocausto que desembocó en la segunda guerra mundial, viéndose las bases del sistema penal moderno alteradas.

Aquello fueron los rasgos de un sistema penal fuertemente presionado por los sistemas políticos autoritarios para obtener respuestas penales a la necesidad de orden. La fase, a la que se puede denominar como la del constitucionalismo social, fue la que despertó y alentó la necesidad de llevar la intervención punitiva de los Estados democráticos a proteger necesidades sociales básicas.

De esta manera, tratar de aprehender esta realidad solo desde la óptica penal, constituye una mirada reduccionista, que amenaza con erigir un constructo excesivamente abstracto y descontextualizado, es por esto que Ambos y Böhm acertadamente catalogan estas figuras como "una estrategia de lucha y supresión de la oposición política" (2009, p. 198).

Así no es de extrañar que durante los períodos de dictadura en Latinoamérica, con cierta influencia de las doctrinas del "derecho penal del enemigo" de Jakobs y Cancio Melia (2003, p. 36), en el plano normativo, se relativizaran las garantías debidas por el Estado, para hacer frente a este estado de emergencia, esta lucha contra los disidentes, a los que se consideraba enemigos internos. Se denominaba enemigos a los "individuos" que en Chile no concordaban con las ideologías de derecha, rotulándolos erradamente a todos de "comunistas", los que fueron perseguidos y sometidos a tortura y desaparición forzosa, acusándolos de pertenecer a "organizaciones de izquierda" con las que el país se encontraba en guerra, por haberse apartado del Derecho de un modo duradero, no garantizando la seguridad cognitiva de su comportamiento.

Lo anterior guarda especial relación con la denominada "Doctrina de la Seguridad Nacional”, consistente en una concepción social global originada desde un ángulo eminentemente militar (PADILLA, 2010, p. 16), destinada a plantear un escenario de emergencia en el cual es indispensable luchar por la seguridad del país. Esta doctrina surge para hacer frente a variados procesos sociales y culturales: la situación de guerra fría, la revolución cubana, el discurso militar de la contrainsurgencia, el proceso de descolonización en Indochina y Argelia (PADILLA, 2010, p. 16 y ss.). 
Algunos autores se han referido al modelo militar derivado de tal doctrina, denominándolo como modelo amigo-enemigo (POLITOFF; TAPIA, 1983, p. 19 y ss.), siendo caracterizado dicho modelo porque "las facultades de excepción —las únicas que interesan - pueden aparecer, adornadas o no, con un flujo de inofensivas normas de carácter general. Lo que importa es dotar al régimen de instrumentos técnicos que den apariencia de legitimidad a una política entendida como supresión del enemigo"4.

De similar forma, el informe redactado por la "Comisión Nacional de Verdad y Reconciliación" señala que la motivación principal perseguida por quienes perpetraban estos delitos era la de "justificar la destrucción de un enemigo interno a quien se le atribuye atentar contra valores superiores y permanentes" 5 .

Tal contexto y doctrina explican el fin estratégico que se plantea tras el empleo de los delitos en cuestión, de manera que no es de extrañar que los agentes del estado dictatorial detuvieran ilegalmente a miles de personas, muchas de las cuales aún se ignoran sus paraderos.

Frente a todo lo expuesto en este apartado, de manera preliminar, podemos afirmar, siguiendo a Muñoz Conde (2008, p. 53), que en un Estado de derecho democrático y respetuoso con la dignidad del ser humano, nadie puede ser nunca definido como no persona, siendo el Derecho Penal un sistema de imputación cuyas reglas se fijarían en virtud del "acuerdo" de las personas que integran la sociedad sobre criterios, que no pueden desvincularse de un contenido valorativo y concepción del ser humano y de la sociedad.

\section{BREVE PANORAMA DEL JUZGAMIENTO DE LOS IMPUTADOS POR LOS DELITOS DE DETENCIONES ILEGALES Y DESAPARICIÓN FORZADA DE PERSONAS}

La conclusión de la Segunda Guerra mundial planteó la necesidad de que las potencias vencedoras acordaran no solo los términos de fin del conflicto, sino además previeran ciertas garantías para que esta paz naciente perdurara. Se dictaron así una serie de instrumentos internacionales en materia de Derechos Humanos. A partir de distintos juicios como el de "Núremberg" (1945-1946), se fue desarrollando una doctrina y una serie de jurisprudencia que promovían la necesidad de prevenir que similares sucesos a los vividos tuvieran lugar y de contar con instrumentos internacionales que permitieran juzgar a estos enemigos de la paz. Necesidad que fue confirmada a partir de los desastres y masacre de la guerra de los Balcanes.

Así las cosas, a paso lento, la comunidad internacional ha acordado que una serie de conductas sean consideradas como crímenes de lesa humanidad; comprometiendo, de esa forma, a la comunidad en general y a los Estados en particular, a investigar, perseguir y sancionar a los culpables de tales delitos.

Lo anterior evidencia una de las ideas matrices a través de la cual se estructura este ordenamiento internacional, la lucha contra la impunidad. Tal noción a decir de Ambos 
(2006, p. 21), constituye un elemento que permite entender la relación entre el Derecho Penal Internacional y los Derechos Humanos, principio que aparece claramente reconocido en los párrafos $4 .^{\circ}$ y $5 .^{\circ}$ del preámbulo del Estatuto de Roma de la Corte Penal Internacional.

A su vez esta lucha contra la impunidad se encuentra normativamente apoyada en dos principios de gran importancia: el de la imprescriptibilidad y el de la proporcionalidad de las penas.

Como señala Rodrigo Lledó, “[...] la prescripción, en materia penal, consiste en la extinción de la responsabilidad penal por el transcurso del tiempo, contado desde la comisión del delito o falta o desde la imposición de la pena” (LLEDÓ VÁSQUEZ, 2000 , p. 111). Es común que las legislaciones de los distintos Estados consagren que tras el transcurso de ciertos plazos, desde la comisión de los delitos, extingan la responsabilidad penal de quienes los cometen, principalmente por razones de paz social y de seguridad jurídica. Justamente para alcanzar esta paz y seguridad, se ha determinado que, en casos de crímenes de guerra o de lesa humanidad, sea necesario prescindir de tal institución.

La imprescriptibilidad de los crímenes de lesa humanidad se encuentra expresamente consagrada en la "Convención sobre imprescriptibilidad de los crímenes de guerra y de los crímenes de lesa humanidad”, de 1968. Si bien dicho tratado no se encuentra ratificado por Chile, teniendo el carácter de vinculante a raíz de su calidad de norma de ius cogens o principio general del derecho internacional, lo que ya ha partir del 2007 la Sala Penal de la Corte Suprema ha asumido a través de algunas de sus sentencias. ${ }^{6}$

Tal doctrina ha sido además confirmada sucesivamente por los fallos de la Corte Interamericana de Derechos Humanos, a través de los fallos: "Almonacid Arellano y otros vs Chile", 7 el "Caso la Cantuta vs Perú", 8 y por el paradigmático fallo por el "Caso Simón” de la Corte Suprema de Justicia de la Nación Argentina. ${ }^{9}$

En cuanto al fin perseguido por la imprescriptibilidad, señala Humberto Nogueira, que "[...] la comunidad mundial busca que tales crímenes no sean olvidados y que el transcurso del tiempo no afecte sus posibilidades de sanción como ocurre en todas parte del planeta, respecto de los cuales no puede aplicarse la prescripción que es el transcurso del tiempo que lleva al olvido de la responsabilidad en la concreción del delito" (2008, p. 583).

Siendo esta la situación, la comunidad internacional ha intentado establecer un imperativo ético-jurídico a los Estados particulares, para evitar el olvido de tales hechos y para tender a la búsqueda de justicia. A lo anterior se refiere Gonzalo Aguilar,

los crímenes internacionales han disuelto el estatuto de limitación temporal penal, y el impedimento de persecución. En efecto, desde comienzos del siglo XX e incluso desde antes, de manera expresa y efectiva, el Derecho 
Internacional, decidió poner fin a esta vinculación entre el tiempo y la memoria, para los crímenes internacionales. A partir de esta época, recordar será un deber tanto ético como jurídico. Recordar -lo cual se encuentra vinculado a la búsqueda de la verdad y al derecho a la verdad- es más que nunca un imperativo moral. Recordar es un tipo de reparación en la medida que la memoria nos pide perdón por aquello que no pudo ser ni impedido ni detenido. (2008, p. 154)

Otro de los principios que en forma similar contribuye en la lucha contra la impunidad tratándose de crímenes de lesa humanidad es el de proporcionalidad, bajo el cual subyace la idea de que la pena a aplicar, para el caso concreto, debe ser establecida tomando especialmente en cuenta el daño provocado por el delito, de manera que para contribuir a la búsqueda de justicia tal pena no resulte irrisoria ni ilusoria.

Normalmente este principio es reconocido, dentro de los distintos ordenamientos penales como una garantía para el imputado, de forma de contener un ejercicio excesivo del poder punitivo del Estado. Sin embargo, en materia internacional, dicho principio se establece como una garantía para las víctimas de graves violaciones a los derechos humanos, de forma que las penas decretadas no constituyan una mera ilusión de justicia.

El principio de proporcionalidad es reconocido, entre otros, en el fallo de la Corte Interamericana de Derechos Humanos llamado caso de "La Masacre de la Rochela vs Colombia”, que de manera expresa consideró: "que en la investigación de graves violaciones a los derechos humanos sea imposible reconocer como compatible con la Convención Americana la imposición de penas ínfimas o ilusorias, o que puedan significar una mera apariencia de justicia”. ${ }^{10}$

Para los fines de este trabajo, podemos entender que el panorama del enjuiciamiento de los crímenes de lesa humanidad cometidos durante la dictadura militar puede dividirse, a grandes rasgos, en dos etapas sucesivas.

En primer lugar, una etapa que abarca el período de la transición democrática, hasta la dictación del fallo de la Corte Interamericana de Justicia por el caso "Almonacid Arellano y otros vs Chile” (de 1990 a 2006). ${ }^{11}$ Período en el que sostenemos se extiende una doctrina política y judicial de plena impunidad, caracterizada por la amplia concesión de la amnistía a los culpables, beneficio establecido en un decreto promulgado por la propia junta militar.

Como punto de transición hacia una nueva etapa, el fallo "Almonacid Arellano y otros vs Chile” es de vital importancia y funda un punto de inflexión, pues establece, entre otras cosas, la responsabilidad internacional de Chile por incumplimiento de diversas normas de índole internacional, fundamentadas principalmente en la ilegal aplicación que se venía haciendo del Decreto Ley n. 2.191 de 1978, que permitía amnistiar a quienes habían cometidos crímenes de lesa humanidad durante la dictadura 
militar, situación que contraría varias disposiciones de la Convención Americana de Derechos Humanos, suscrita y vigente en Chile.

Dentro de las distintas consideraciones que establece el fallo, es especialmente esclarecedora la contenida en el párrafo 129:

El Tribunal, como conclusión de todo lo señalado en esta sección A), considera que el asesinato del señor Almonacid Arellano formó parte de una política de Estado de represión a sectores de la sociedad civil, y representa solo un ejemplo del gran conjunto de conductas ilícitas similares que se produjeron durante esa época. El ilícito cometido en contra del señor Almonacid Arellano no puede amnistiarse conforme a las reglas básicas del derecho internacional, puesto que constituye un crimen de lesa humanidad. El Estado incumplió su obligación de adecuar su derecho interno a efectos de garantizar los derechos establecidos en la Convención Americana, porque mantuvo y mantiene en vigencia el Decreto Ley n. 2.191, el que no excluye a los crímenes de lesa humanidad de la amnistía general que otorga. Finalmente, el Estado violó el derecho a las garantías judiciales y a la protección judicial, e incumplió con su deber de garantía, en perjuicio de los familiares del señor Almonacid Arellano, porque aplicó el Decreto Ley n. 2.191 al presente caso. ${ }^{12}$

Posterior a esto, una segunda etapa estaría representada por un proceso de impunidad parcial, caracterizada por la condenada de ex militares y agentes de la dictadura militar, pero con la generalizada aceptación de atenuar dichas penas a través de la circunstancia modificatoria de media prescripción o prescripción gradual, consagrada en el artículo 103 del Código Penal, lo que significó, al final de cuentas, bajas condenas con la concesión de beneficios de libertad vigilada y remisión condicional de la pena. ${ }^{13}$

En relación a lo anterior, la sala penal de la Corte Suprema de Chile ha venido sosteniendo reiteradamente, a lo menos desde el año 2007, que la media prescripción del artículo 103 del Código Penal de Chile no es una prescripción propiamente tal, sino una atenuante especial de la pena, de manera que la imposibilidad de aplicar la institución de la prescripción de la acción penal, que es causal de extinción de la responsabilidad criminal, no alcanza a la denominada media prescripción, o gradual, parcial o incompleta, como también se le denomina, la que es motivo solo de atenuación de la pena, de acuerdo al artículo $103 .^{\circ}$ del estatuto punitivo.

En este contexto es que al 11 de septiembre de 2010 se puede señalar que de un total de 75 causas falladas por la Corte Suprema de Chile, hay 43 sentencias en las que se aplicó la media prescripción, con la rebaja considerable de penas a los hechores, que gozan casi de inmediato de libertad y de otros beneficios carcelarios que no son aplicables a los crímenes de lesa humanidad. ${ }^{14}$ 
Los efectos que sobre el ius puniendi estatal provoca la denominada media prescripción, son distintos, debido que al tratarse de una circunstancia atenuante, ésta solo permite introducir una rebaja a la pena correspondiente y aunque su fundamento es también el transcurso del tiempo, en lo que se asemeja a la causal extintiva de la prescripción, no puede asimilársele jurídicamente, ya que esta última descansa en el principio de la seguridad jurídica (POLITOFF; MATUS; RAMÍREZ, 2004, p. 578).

La prescripción encuentra su justificación en la necesidad social de buscar la estabilización de situaciones, aún de hecho, como son las de elusión prolongada de la responsabilidad penal que a alguno quepa, para que no se convierta en indefinida la aplicación de los preceptos penales y no subsista un estado permanente de incertidumbre respecto del que cometió un hecho punible, en cuanto a si hay responsabilidad criminal de su parte. Esto explica que todas las legislaciones contengan preceptos que declaran extinguida la responsabilidad penal después de transcurridos ciertos plazos (NOVOA, 2005, p. 402).

En cambio la media prescripción, según la jurisprudencia chilena, como una circunstancia dirigida únicamente a menguar la responsabilidad penal emanada del delito, con el mismo efecto jurídico que producen las circunstancias atenuantes genéricas establecidas en el artículo 11 del Código Penal, difiere de la prescripción, dado que a ella no le son aplicables los principios y fundamentos que determinan la imprescriptibilidad de la acción penal persecutoria de los delitos de lesa humanidad, con lo que se evita su total impunidad.

Sin embargo "El propósito y consecuencia de la media prescripción en estos delitos de lesa humanidad en Chile, ha sido reducir significativamente las penas aplicables a los responsables de delitos de tal naturaleza, permitiéndoles de esta manera hacerse acreedores de beneficios tales como la 'libertad vigilada' o la 'remisión condicional de la pena’ que, en la práctica, implican impunidad” (QUEZADA, 2011, p. 164).

\section{ANÁlisis de la JURisPrudencia aCerca del tratamiento QUE SE LE OTORGA EN CHILE A LA MEDIA PRESCRIPCIÓN EN} EL DELITO DE DESAPARICIÓN FORZADA DE PERSONAS

Tal como se anunció al inicio de este trabajo, para comprender como ha operado la aplicación del beneficio de la media prescripción en los juicios por desaparición forzada de personas, ocurridos durante el Régimen Militar, es necesario efectuar un breve análisis de fallos dictados durante los últimos cinco años, representativos de una práctica interpretativa, que ha permitido a quienes han sido condenados por crímenes de lesa humanidad, cumplir sus penas en regímenes de libertad.

Como anticipo, puede señalarse que la sala penal de la Corte Suprema de Chile sostiene reiteradamente, ya en democracia y a lo menos desde el año 2007, que la prescripción gradual o la denominada media prescripción del artículo 103 del Código Penal 
de Chile no es una prescripción propiamente tal, sino una atenuante especial de la pena. Institución independiente de la prescripción de la acción o de la pena cuyos fundamentos, en cuanto al transcurso del tiempo, y consecuencias jurídicas, son diversos, no obstante que ambas instituciones se encuentren reguladas en un mismo título del Código Penal. Por ende, en visión de la Corte Suprema, no operan las restricciones del derecho internacional penal ni del derecho local, para la aplicabilidad de la denominada media prescripción a los delitos contra la humanidad.

Es así que,

tras el período anterior caracterizado por fallos que declaraban la imprescriptibilidad de los homicidios y secuestros cometidos durante la dictadura, por constituir delitos de lesa humanidad, a mediados del año 2007 se inicia una nueva etapa en la jurisprudencia, que no implica una incongruencia entre distintos fallos, sino algo mucho más sorprendente, la contradicción se evidencia en el contenido de los propios fallos, pues delitos que son descritos como imprescriptibles, acto seguido y en los mismos fallos son declarados gradualmente prescritos, aplicando la normativa del artículo 103 del Código penal a delitos que nunca prescribirán. (FERNÁNDEZ, 2010, p. 481)

Es a partir del pronunciamiento sobre la casación presentada en el caso de Juan Rivera Matus ${ }^{15}$ que la Corte Suprema ha construido, una nueva línea jurisprudencial, caracterizada por la concesión a los responsables, de oficio y en toda su extensión, del beneficio de la prescripción gradual.

Prueba de esta reiterada y contradictoria jurisprudencia lesiva de los tratados internacionales de derechos humanos, lo es también el fallo de la Corte Suprema sobre el emblemático caso de "Los Hermanos Vergara Toledo", por el cual cada año en Chile miles de jóvenes en las calles, conmemoran el alevoso homicidio de estos jóvenes, en el denominado "Día del joven combatiente". ${ }^{16}$

El presente análisis tendrá como foco central cinco fallos de nuestra Corte Suprema de Justicia ${ }^{17}$ en base a los cuales se procederá a exponer los pilares argumentales sobre las cuáles se ha pretendido legitimar y aplicar esta atenuante a los condenados por delitos de lesa humanidad, para luego efectuar el análisis crítico de tales postulados, a la luz de la normativa internacional y de los aportes que se han formulado dentro del ámbito académico.

De forma mayoritaria se ha asentado en el seno de nuestra práctica judicial la aceptación de la procedencia del beneficio de media prescripción o prescripción gradual, basada principalmente en los siguientes motivos:

1. $\left.{ }^{\circ}\right)$ La Corte Suprema ha estimado que la imposibilidad de aplicar la prescripción de la acción penal derivada de los compromisos internacionales asumidos por Chile, 
no implica la imposibilidad de aplicar la denominada atenuante de media prescripción, establecida en el Código Penal; el mandato así de imprescriptibilidad que imponen los distintos instrumentos internacionales no se extendería a la prescripción gradual. En ese sentido se ha señalado que:

[...] siendo la prescripción de la acción penal una causal extintiva de la responsabilidad penal, claramente distinguible de la atenuante calificada establecida en el citado artículo 103 del estatuto punitivo, ambas con efectos penales totalmente distintos, los argumentos dirigidos a rechazar una y otra no pueden ser los mismos, ni pueden mezclarse. Aun tratándose de instituciones jurídicas con un origen común y que se nutren del tiempo transcurrido desde la perpetración del ilícito, la sentencia que rechaza la invocación de la "media prescripción", en cuanto permite una rebaja de la cuantía de la pena asignada al delito, utilizando, en esencia, iguales razones a las esgrimidas para desestimar la extinción de la responsabilidad criminal [...]. ${ }^{18}$

[...] tampoco escapa a estos sentenciadores que la institución de la "media prescripción” - como circunstancia de atenuación muy calificada de la responsabilidad penal — se encuentra consagrada en nuestro Código Penal desde la época de su dictación en mil ochocientos setenta y cuatro encontrándose el juzgador, conforme a lo menos en base de dos parámetros: el tiempo transcurrido y el mérito de autos. En consecuencia, no se divisa antecedente que permita concluir de jure, que el Estado como o en cuanto componente o miembro del concierto internacional, con motivo de consagrar por demás, excepcionalmente, la imprescriptibilidad para estos crímenes, hubiere renunciado o tuviere que restarse de aplicar la atenuante consistente en la media prescripción, lo que ocurriría solo - en el caso a caso- si lo estimare en Justicia pertinente. ${ }^{19}$

La doctrina sustentada en tales pronunciamientos se apoyaría en la circunstancia que los efectos que el Código Penal asignaría a tales instituciones serían distintos; así tratándose en la prescripción de la acción penal el efecto sería la extinción de la responsabilidad penal, mientras que la prescripción gradual produciría una notable atenuación de la pena a aplicar, en otras palabras:

La prescripción extingue la responsabilidad penal ya ejercida e impide la aplicación de toda sanción punitiva, siendo sus motivos histórico-políticos, jurídicos, humanitarios y otros muy conocidos. Los efectos que sobre el ius puniendi estatal provoca la denominada media prescripción son totalmente distintos, desde que al tratarse de una circunstancia atenuante ésta solo 
permite introducir una reducción de la pena correspondiente y aunque su fundamento es también el transcurso del tiempo, en lo que se asemeja a la causal extintiva, no puede asimilársele jurídicamente, ya que esta última descansa en el principio de la seguridad jurídica. ${ }^{20}$

2. ${ }^{\circ}$ ) Por otro lado, la E. Corte Suprema también ha establecido una línea jurisprudencial para determinar desde cuándo debe comenzar a contarse el plazo para computar la media prescripción. En relación a este punto se ha sostenido:

[...] el delito pesquisado es susceptible de estimarse consumado desde el momento en que se llegó al día noventa y uno de encierro de la víctima, lo que ocurre en el caso en análisis desde fines diciembre de mil novecientos setenta y tres, fecha cierta que permite precisar el inicio del término que es necesario considerar para la procedencia de la institución que se analiza. Así resulta que contado el plazo de la prescripción de la acción penal desde la fecha de comisión del hecho, hasta aquella en que se interrumpió, en mayo de 1991 y, más tarde, en abril de 2001 cuando se presentó querella criminal y de acuerdo, además, a lo dispuesto en el artículo 96, en consonancia con el artículo 103, ambos del Código Penal, ha de considerarse que a partir de la fecha del injusto hasta cualquiera de esas datas, transcurrió en exceso el plazo de cinco años antes señalado, cumpliéndose así la hipótesis temporal a la que alude el mencionado artículo 103 del Código Penal, por lo que habrá de reconocerse concurrente la aludida atenuante de responsabilidad penal. ${ }^{21}$

La fórmula que el órgano jurisdicente adopta es la de computar el comienzo del plazo de prescripción, desde que se configura la circunstancia que permite subsumir los hechos al delito de secuestro agravado, ${ }^{22}$ empleándose dicho plazo de 90 días tanto para calificar la conducta como para iniciar el conteo de los días que constituyen el curso de la prescripción. De esa manera, se confirma el alarmante precedente, ya adoptado en fallos anteriores, que: tratándose del delito de secuestro, el plazo que comienza a correr desde el día 91 contado desde la detención o encierro de la víctima y que permitía entender que tal acción era constitutiva de secuestro calificado, implicaba también el inicio del curso de la prescripción; que si bien no daría lugar a la extinción de la responsabilidad penal de los partícipes en delitos de lesa humanidad, si les permitiría, tras el transcurso de 5 años acceder al beneficio de media prescripción. ${ }^{23}$

A partir de estas bases se ha pretendido legitimar una práctica recurrente: la concesión del beneficio de media prescripción a condenados por delitos de lesa humanidad, sin embargo tal línea argumental ha sustentado una serie de planteamientos que a juicio de alguna doctrina no deben ser aceptados. Procede entonces analizar la solidez de tales 
bases argumentales y contrastarlas con las normas internacionales respectivas y con aportes doctrinales relevantes.

En primer lugar, no caben dudas acerca de que la prescripción extintiva — de la acción o de la pena - es germen de impunidad; así lo ha dispuesto expresamente La Convención sobre Imprescriptibilidad de los Crímenes de Guerra y de Lesa Humanidad y la Convención Americana sobre Derechos Humanos, entre otras normas internacionales ${ }^{24}$ y los ya citados fallos de la Corte Interamericana de Derechos Humanos. ${ }^{25}$ Pero cabe plantearse si efectivamente la prescripción gradual no sería fuente de impunidad en tales casos, tal como ha sostenido nuestro más alto tribunal.

Para este análisis, es necesario determinar qué persigue la comunidad internacional al disponer que los delitos de lesa humanidad sean imprescriptibles.

De acuerdo a lo planteado por Nogueira (2008, p. 583), la comunidad mundial busca que tales crímenes no queden en el olvido, y que el transcurso del tiempo no se transforme en un impedimento para la imposición de sanciones.

Tal fundamento, compartido mayoritariamente, se encontraría vinculado a un fin preventivo general que se le asigna a la pena para tales casos. En ese sentido la imposición de la pena para los delitos de lesa humanidad se justifica — aún a pesar del transcurso del tiempo - ya que tales crímenes no se borran tan rápido de la memoria, por el contrario la demanda de penalización pervive en ellos y se hace especialmente necesaria para recordar a la comunidad la gravedad de tales sucesos y para evitar su repetición.

Más allá que los efectos de la prescripción extintiva y de la media prescripción sean distintos, tal hecho no puede llevarnos al extremo de disociar completamente tales instituciones — como han hecho los citados fallos_ las cuales comparten más similitudes que diferencias: la base de ambas es el transcurso del tiempo y los efectos, en ambas instituciones, recaen sobre la pena a imponer, así mientras la prescripción extintiva impide la imposición de pena alguna, la gradual atenúa la pena a imponer.

Atendiendo a lo expuesto, puede sostenerse que tanto la prescripción extintiva como la media prescripción impiden satisfacer la demanda indeleble de justicia, esta consideración hacia hechos especialmente graves que no debieran ser olvidados; la primera al impedir — en forma absoluta — la imposición de una pena, la segunda al posibilitar una pena que parece irrisoria, demasiada favorable y por ende desproporcionada a la gravedad de los hechos.

Si bien, la conclusión anterior es correcta (la prescripción gradual es germen de impunidad en los casos que es concedida), el fundamento del cual deriva tal conclusión no es del todo exacto. En efecto, como señala Zaffaroni (2005, p. 260), fundamentar la imprescriptibilidad en materia de delitos de lesa humanidad, vinculando dicha fundamentación con fines preventivos generales de la pena, no constituye un buen resguardo; ya que fácilmente podría esgrimirse que tal fundamentación no explica por qué ciertos delitos comunes especialmente graves (v.g., caso de asesinos o abusadores sexuales 
en serie), cuya exigencia de sanción pervive aún a pesar del paso del tiempo, prescribirían, mientras que los delitos de lesa humanidad no. ${ }^{26}$

En razón de lo anterior, propone Zaffaroni, no fundamentar la imprescriptibilidad de los delitos de lesa humanidad a partir de una legitimación del poder punitivo, sino más bien a partir de una concepción agnóstica de éste. En palabras del propio jurista:

El poder punitivo nunca es del todo racional y tampoco lo es cuando se lo aplica a autores de crímenes contra la humanidad. Su irracionalidad emerge ante todo de que los crímenes contra la humanidad son generalmente practicados por las mismas agencias del poder punitivo, operando fuera del control del derecho penal, es decir, huyendo del control y de la contención jurídica.[...] No puede sostenerse razonablemente que sea menester garantizar la extinción de la acción penal por el paso del tiempo, en crímenes de esta naturaleza, en razón de una intolerable irracionalidad en caso contrario.[...] No se trata de que el poder punitivo ejercido contra los criminales de lesa humanidad se halle legitimado, sino que no se halla legitimado el derecho penal para contenerlo más allá de ciertos requisitos básicos fundamentales. [...]La imprescriptibilidad que hoy consagran las leyes y las costumbres internacionales y que otrora no establecían, pero que también deben considerarse imprescriptibles, es fruto de la carencia de legitimidad del derecho penal para contener el poder punitivo en estos casos. (ZAFFARONI, 2005, p. 264-266)

El genocidio y los crímenes contra la humanidad plantean un conflicto que no tiene solución racional: no puede pensarse en una solución reparadora, por ejemplo, y menos aún en los otros modelos de solución de conflictos. Ante la brutal enormidad del ilícito y la falta de modelos de solución racional, el derecho penal prácticamente carece de espacios para limitar el poder punitivo, incluso la venganza privada. Tiene razón Zaffaroni, cuando sostiene que "el poder punitivo es un factum político y lo único jurídico — y ético — es su contención penal que en este caso no estaría legitimada por la enormidad de la lesión” (ZAFFARONI; ALIAGA; SLOKAR, 2002, p. 200), en otras palabras, el injusto es de tal magnitud y el esfuerzo del violador de derechos humanos por alcanzar la vulnerabilidad del sistema penal (por sus hechos criminales) es tan extraordinario que el derecho penal es impotente en su función acotante o limitativa.

A lo anterior se suma la arbitrariedad del Estado que procurará la impunidad de sus crímenes, por el transcurso del tiempo, pues mientras detenta el poder será imposible ejercer acciones para perseguir sus delitos, por eso se plantea la regla de la imprescriptibilidad. En el mismo sentido, con otros matices se plantea que 
la prescripción solo puede correr desde que se pudo ejercer sin impedimentos la acción penal, bajo el conocido principio que "al impedido no le corre plazo”, por consiguiente, solo cabría entender terminado un delito de impunidad (y, por tanto, "cometido") cuando cesa la situación de impunidad: solo entonces podría empezar a correr el plazo de prescripción de la acción penal. (HORVITZ, 2006, p. 224)

Por otro lado, la concesión de media prescripción que han fundamentado los aludidos fallos de nuestra Corte Suprema parece contrariar el mandato de proporcionalidad de la pena establecido en distintos instrumentos internacionales, solo por citar algunos: el artículo 4.2 de "La Convención contra la tortura y otros tratos o penas crueles, inhumanas o degradantes" y el artículo tercero de "La Convención Interamericana sobre desaparición forzada de personas" y como ya se señaló, reconocido también en fallos de la Corte Interamericana de Derechos Humanos.

Referido al deber de proporcionalidad de la pena, establecido en tales instrumentos, señalan Fernández y Sferrazza:

[...] resulta claro concluir, que el orden jurídico debe responder racional y proporcionalmente a la gravedad de los hechos, merced la selección de consecuencias previstas en los ordenamientos. No es admisible sancionar hechos gravísimos con penas levísimas, como sucede a través de procesos "a modo" o fraudulentos, rechazados por los órganos penales internacionales y también por la Corte Interamericana de Derechos Humanos. (2009, p. 308)

Sin embargo, las distintas consideraciones expresadas en los aludidos fallos, de nuestra Corte Suprema, vulneran no solo los principios de imprescriptibilidad y proporcionalidad de la pena, sino también han asentado una doctrina errónea en cuanto a la forma en que debe computarse el plazo a partir del cual contar la fecha de inicio de la prescripción gradual. Lo que implica sostener, en otras palabras, que además de propiciar una impunidad parcial, lo hacen a través de elaboraciones argumentativas erróneas sobre la fecha consumativa del delito de secuestro. Tal determinación es efectuada a partir de una poco afortunada interpretación del artículo 95 en relación al artículo 141 del Código Penal. 27

Para entender lo anterior, cabe señalar que el delito de secuestro es un delito permanente según ha estimado la doctrina mayoritaria. ${ }^{28}$ Por delitos permanentes podemos entender aquellos "[...] que no concluyen con la realización del tipo, sino que se mantienen por la voluntad delictiva del autor tanto tiempo como subsiste el estado antijurídico creado por éste; [...]" (RAFECAS, (2010, p. 81). En ellos, como señala Mañalich, "[...] lo permanente no es la consumación, sino la ejecución del comportamiento delictivo" (2004, p. 14). 
Una de las principales consecuencias que el delito de secuestro sea permanente es que la prescripción solo principia a correr desde el momento en que se logra liberar al secuestrado (GARRIDO MONTT, 2009, p. 390). Entonces es difícil entender que los plazos de prescripción comiencen a correr si el delito sigue ejecutándose, situación que los fallos en estudio pretenden justificar para conceder el beneficio de la media prescripción.

A pesar de lo anterior, la aplicación de dicha fórmula presenta ciertas dificultades tratándose de los casos en estudio, dado que

[...] parece imponer una carga probatoria a los imputados por secuestro, en términos tales que la única forma de liberarse de la imputación por la perduración de la ejecución del secuestro consiste en probar que la víctima del secuestro ya no lo es: o bien por haberse puesto en libertad, o bien por haber pasado de víctima a víctima de homicidio, [...] la acreditación de que el delito se consumó no puede sin más implicar la asunción de que sigue ejecutándose hasta el presente. (MAÑALICH, 2004, p. 15)

La solución para esta dificultad puede conseguirse siguiendo el efecto último que produce la prescripción en un Estado de Derecho: no mantener indefinidamente abierta la contingencia de punición. Así como los delitos de lesa humanidad se sitúan en un contexto en que la punición no es contingente, "[...] la prescripción no puede correr sino una vez que la punición se hace contingente” (MAÑALICH, 2004, p. 32-33).

Es decir, el curso de la prescripción no puede comenzar a correr - de aceptarse erróneamente que procede conceder la media prescripción - sino una vez existan las condiciones, de quienes fueron víctimas de tales delitos o sus familiares, para ejercer las acciones penales y civiles.

\section{El fallo de la Corte Suprema por la causa "Rudy Cárcamo", ¿UNA NUEVA ETAPA EN LA INTERPRETACIÓN DE LA PROCEDENCIA DE LA MEDIA PRESCRIPCIÓN EN CRÍMENES DE LESA HUMANIDAD?}

Con fecha 24 de mayo de 2012, la Segunda Sala de la Corte Suprema, ${ }^{29}$ con ocasión de un recurso de casación en el fondo, invalidó la sentencia de la Corte de Apelaciones, dictada con fecha 25 de noviembre de 2011, que confirmaba la sentencia de primer instancia del Ex Primer Juzgado del Crimen de Talcahuano, de fecha 15 de enero de 2010, que condenaba a los encausados: integrantes del comando operativo del Centro de Inteligencia Regional (CIRE) integrado por el capitán de navío (r) Hugo Nelson González D’Arcangeli; el capitán de navío (r) José Raúl Cáceres González; el oficial de mar (r) Víctor Ernesto Donoso Barrera; el coronel (r) de Carabineros Conrado Alfredo Cesnic Guerricabeitia, y el prefecto inspector (r) de la Policía de Investigaciones de 
Chile, Osvaldo Francisco Harnish Salazar, a 541 días de presidio, como autores del secuestro calificado del dirigente del MIR Rudy Cárcamo Ruiz, favoreciéndose a los condenados con el beneficio de remisión condicional de la pena, gracias a la atenuación a la pena que permitió la media prescripción.

En la sentencia de reemplazo, la Segunda Sala, estableció que la media prescripción no debió haber operado, aumentando en consecuencia la pena de cada uno de los condenados a 5 años y un día de presidio mayor en su grado mínimo. ${ }^{30}$

En cuanto a los fundamentos expuestos para no dar curso a la prescripción gradual, resulta relevante exponer los siguientes considerandos de la sentencia de casación:

TRIGÉSIMO QUINTO: Que para los efectos de la prescripción de la acción penal — sea total o gradual — necesariamente ha de considerarse la naturaleza o carácter del delito en cuanto a su estado de consumación, esto es, si se trata de ilícitos de ejecución instantánea o permanente, pues ello habrá de determinar el inicio del cómputo del respectivo plazo de prescripción. En tal perspectiva, el secuestro es de aquellos que la doctrina conoce como de ejecución permanente, pues perdura en el tiempo su momento consumativo. En la especie, se produce un instante en que la conducta típica se completa, pero se origina un estado o situación susceptible de ser prolongado en el tiempo, que constituye subsistencia de esa acción: el delincuente encierra a su víctima y su conducta típica queda completa con ello (consumación), pero el encierro o detención (el resultado) empieza a perdurar y puede prolongarse más o menos según la voluntad del hechor. Esta mantención o subsistencia de la conducta típica plena, puede darse solamente en ciertos tipos que emplean un verbo denotativo de una acción susceptible de duración. .......]

TRIGÉSIMO SEXTO: Que, como ya se dijo, entre las particularidades prácticas importantes que presentan los delitos de consumación permanente resalta aquella de que la prescripción de la acción penal no empieza a correr sino una vez que ha concluido la prolongación del resultado....[...]

TRIGÉSIMO SÉPTIMO: Que, la circunstancia de que atendida la naturaleza de permanente del delito que ha quedado establecido, se carece de un hecho cierto para precisar el comienzo del término necesario para la prescripción, que ha de contarse desde el momento de consumación del delito, conforme lo dispone el artículo 95 del Código Penal, lo cual no se ha dado en el tiempo por la situación señalada. La disposición del artículo 103 del estatuto punitivo gira en torno al "tiempo de la prescripción de la acción penal o de la pena”, cuya mitad debe haber transcurrido. Este decurso de un plazo, ha de tener, ya que de otra manera no puede contarse hacia adelante, un momento fijo de inicio, de comienzo, por lo que en un delito 
cuya agresión al bien jurídico tutelado perdura y se extiende hasta que no se produce determinado evento, tal precisión es imposible. [...]

En consecuencia, equivocadamente se acogió el reconocimiento de la denominada "media prescripción" y de la rebaja de la pena que se solicitaba por dichas defensas como consecuencia de su aceptación. ${ }^{31}$

En suma, la resolución transcrita entiende que el secuestro al ser un delito de consumación permanente no puede a su respecto contarse el curso de la prescripción de la acción penal, son una vez que haya concluido la prolongación del resultado. Así, señala el fallo que, al carecer de un hecho cierto que permita precisar el comienzo del término necesario para la prescripción (que señala ha de contarse desde el momento de consumación del delito), no podría darse lugar a la prescripción ni a la media prescripción, ya que solo en el evento de determinarse en qué lugar se encuentra la víctima podría comenzar a contarse el plazo de prescripción y si se hubiere producido su fallecimiento, habría que determinar la data de tal hecho para comenzar el cómputo de la prescripción.

El anterior aserto, si bien significa un avance en el proceso de búsqueda de verdad, justicia y reconciliación, plantea una serie de dificultades.

En primer lugar, la construcción que se hace de los delitos permanentes no parece precisa, pues en los delitos permanentes lo permanente no es la consumación (como erróneamente se sostiene en el fallo), sino que lo que perdura es un determinado estado antijurídico, así la consumación puede verificarse en un instantes preciso (instantánea) y luego esfumarse, pero subsistir tras ella un estado delictual que no se desvanece. Como se ha señalado con anterioridad, "lo permanente no es la consumación, sino la ejecución del comportamiento delictivo” (MAÑALICH, 2004, p. 14).

En segundo lugar, que se entienda que los delitos se siguen ejecutando dado que no hay noticias de las víctimas (vivas o muertas) — que se entiende siguen secuestradasimplica entregar una carga probatoria a los acusados, que riñe con las posibilidades de actuación procesal en juicio, y que excede el afán de lucha contra la impunidad plasmada en los instrumentos internacionales.

Por último, el fallo no se hace cargo de un aspecto de gran importancia, y que constituye, según lo desarrollado hasta ahora, el asunto principal de la cuestión en estudio, ¿vulnera la institución de la media prescripción los principios de imprescriptibilidad y de proporcionalidad de las penas?

Si bien el mencionado fallo constituye un avance, al no entregar una respuesta de fondo acerca de la compatibilidad de la institución de media prescripción con la normativa internacional en materia de imprescriptibilidad y de proporcionalidad de las penas, se corre el riesgo de volver a entender que el citado beneficio es procedente, pues la construcción que pretende deslegitimarlo (y que ha sido expuesta en el fallo en análisis) no parece capaz de salir airoso al paso de críticas dogmáticas. 


\section{CONCLUSIÓN}

En un Estado de derecho democrático y respetuoso con la dignidad del ser humano, nadie puede ser nunca definido como no persona, siendo el Derecho Penal un sistema de imputación cuyas reglas no pueden desvincularse de un contenido valorativo y concepción del ser humano y de la sociedad. Por lo que es indudable que la normativa propia de una desaparición forzada de personas por parte del Estado, debió estar siempre contemplada en nuestra legislación nacional y no imponer a los tribunales la obligación de juzgar este tipo de conductas como secuestro, delito que puede ser cometido en forma genérica por un particular.

Adicionalmente, el hecho que no se contemplara expresamente en un compromiso internacional suscrito por Chile, la imposibilidad de aplicar la media prescripción como atenuante a los delitos de lesa Humanidad, no quiere decir que el Estado Chileno no debiera excluir expresamente este beneficio de estos delitos que se tornan especialmente graves, por ser cometidos por el Estado, entidad encargada de la protección de las personas.

Por otra parte, no cabe duda que las penas resultantes de la aplicación de la prescripción gradual, por los delitos de lesa humanidad cometidos durante el Régimen Militar, que en su mayoría varían de 3 años y un día a 5 años de presidio menor, y que en definitiva se cumplen en libertad debido a los beneficios que concede la Ley n. 18.216, resultan irrisorias y desproporcionadas, contrariando así el mandato establecido en los mencionados instrumentos internacionales.

De forma tajante puede establecerse que la institución de la media prescripción en delitos de lesa humanidad conspira en la lucha contra la impunidad buscada para estos efectos por la comunidad internacional, existiendo de parte del Estado de Chile una violación de los principios de imprescriptibilidad y de proporcionalidad, que forman parte del denominado ius cogens o principios generales del derecho internacional.

Por último, no creemos que la solución siga la senda de derogar el artículo $103^{a}$ del Código Penal, puesto que es una reconocida garantía que parta en términos de paz social y seguridad jurídica, tratándose de delitos comunes, lo cual no acontece en el caso de los delitos de lesa humanidad, los cuales perduran en la memoria nacional e internacional y especialmente en la de las víctimas. 
NOTAS

1 Práctica que deriva de la doctrina conocida como Doctrina de la Seguridad Política, profusamente difundida y puesta en práctica en los gobiernos dictatoriales y autoritarios a partir de la década de los 60 en América Latina. Una completa descripción del fenómeno: Padilla Ballesteros (2010, p. 15 y ss.).

2 Ragués menciona también que el artículo 5 de la "Convención Internacional de Naciones Unidas para la protección de todas las personas contra las desapariciones forzadas", otorga carácter de "delito de lesa humanidad” a la desaparición forzada de personas cuando constituyan prácticas "sistemáticas y generalizadas” (RAGUÉS, 2010, p. 46).

3 La aplicación de concurso, que abarque como un solo delito el acto cometido es inaceptable, en atención a que el bien jurídico protegido se trata de la vida y libertad de las personas, valores esenciales a todo ser humano, así por tanto, el tipo penal se colma y agota con el atentado particular a cada una de las víctimas (RAFECAS, 2010, p. 82).

4 Informe de la Comisión Nacional de Verdad y Reconciliación, v. 1, t. II, p. 746. Disponible en formato digital en el sitio web: <http://www.ddhh.gov.cl/ddhh_rettig.html>. Accedido el: 14 jun. 2013.

5 Idem.

6 Desarrollando el carácter vinculante de tal principio: Nogueira Alcalá (2008, p. 583 y ss.).

7 Corte Interamericana de Derechos Humanos, fallo "Almonacid Arellano y otro vs Chile”, Sentencia de fecha 26 de septiembre de 2006, párrafo n. 153, disponible en formato digital en el sitio web de la CIDH: <http:/ /www.corteidh.or.cr/ docs/casos/articulos/seriec_154_esp.pdf>. Accedido el: 21 jun. 2013.

8 Corte Interamericana de Derechos Humanos, fallo "La Cantuta vs Perú", Sentencia de fecha 29 de noviembre de 2006, párrafo n. 225, disponible en formato digital en el sitio web de la CIDH: <http://www.corteidh.or.cr/docs/ casos/articulos/seriec_154_esp.pdf>. Accedido el: 21 jun. 2013.

9 Sentencia Corte Suprema de Justicia de la Nación Argentina, causa n. 17.768, "Simón, Julio Héctor y otros s/ privación ilegítima de la libertad, etc.”, jun. 2005.

10 Corte Interamericana de Derechos Humanos, fallo "La Masacre de la Rochela vs Colombia”, Sentencia de fecha 11 de mayo de 2007, párrafo n. 191, disponible en formato digital en el sitio web de la CIDH: <http://www.corteidh.or.cr/ docs/casos/articulos/seriec_163_esp.pdf>. Accedido el: 22 jun. 2013.

11 Establecer un período anterior a este no tendría sentido. Relatan Sofía Correa y otros acerca del funcionamiento del Poder Judicial durante el período de dictadura: "El Poder judicial, única rama constitucional que no sufrió descabezamiento, amén de no pronunciarse en defensa de los derechos conculcados, tampoco los protegió. De los 5.000 recursos de amparo presentados a los tribunales de justicia entre el 11 de septiembre de 1973 y comienzos de 1979, solo uno fue acogido" (CORREA, 2001, p. 283).

12 Corte Interamericana de Derechos Humanos, fallo "Almonacid Arellano y otro vs Chile", Sentencia de fecha 26 de septiembre de 2006, párrafo 129.

13 Es posible encontrar un estudio detallado y completo de los fallos dictados por la Corte suprema en casos de delitos de lesa humanidad en: Fernández; Sferrazza (2009, p. 319 y ss.).

14 Documento "Los Derechos Humanos y la Corte Suprema de Chile, su "Media Prescripción”, ¿Un punto final encubierto? Carta dirigida al Presidente de la Corte Suprema de Chile, el 11 de septiembre de 2010 por la Asociación Americana de Juristas Valparaíso/Aconcagua. Disponible en: <http://www.aajvalparaisoaconcagua.cl/muestra_noticias. asp?id=ycgkox\#up>. Accedido el: 22 jun. 2013.

15 Sentencia de la Corte Suprema de Chile, del 30 de julio de 2007, rol n. 3808-06.

16 Sentencia de la Corte Suprema de Chile, del 4 de agosto de 2010, rol n.7089-09. 
17 Los fallos empleados en el presente trabajo que fueron dictados durante el período de 2008 a 2012, son los siguientes: 1) Resolución Corte Suprema en causa rol n. 2422/2008, dictada el 11 de diciembre de 2008; 2) Resolución Corte Suprema en causa rol n. 874/2008, dictada el 27 de enero de 2009; 3) Resolución Corte Suprema en causa rol n. 925/2009, dictada el 7 de septiembre de 2009; 4) Resolución Corte Suprema en causa rol n. 3378/2009, dictada el 29 de septiembre de 2009; 5) Resolución Corte Suprema en causa rol n. 2414/2010, dictada el 21 de abril de 2011; y 6) Resolución Corte Suprema en causa rol n. 288-12. dictada el 24 de mayo de 2012.

18 Considerando Cuarto, sentencia Corte Suprema, causa rol n. 874/2008. En el mismo sentido sentencia Corte Suprema, causa rol n. 975/2009.

19 Considerando Octavo, sentencia Corte Suprema, causa rol n. 2422/2008.

20 Considerando Primero, sentencia Corte Suprema, causa rol n. 2414/2010. En el mismo sentido, sentencia Corte Suprema, causa rol n. 3378/2009.

21 Considerando Séptimo, sentencia Corte Suprema, causa rol n. 2414/2010.

22 El artículo $141 .^{\circ}$ del Código Penal, antes de la modificación efectuada por la Ley n. 18.222 de 1983, establecía como circunstancia agravante del delito de secuestro, que el encierro o la detención se prolongare por más de 90 días, plazo que tras la citada modificación, fue rebajado a 15 días.

23 Guzmán (2009, p. 68) hace referencia a otra fórmula adoptada en fallos anteriores, que genera aún mayor perplejidad, la de determinar como inicio de plazo a partir del cual contar el curso de la prescripción gradual, la fecha en que el militar acusado, se acogió al retiro de filas, entendiéndose que al cesar el mando militar, acabó su poder delictivo dentro de la organización.

24 Es importante tener presente que los diversos tratados internacionales sobre la materia no establecen de manera originaria la imprescriptibilidad de los delitos de lesa humanidad, sino que se limitan a reconocer tal característica, que debe su origen al Derecho Consuetudinario Internacional que integra el denominado ius cogens.

25 Punto expuesto en el apartado segundo del presente trabajo.

26 Zaffaroni de la misma manera explica que otros fundamentos de la prescripción, anclados a teorías retributivas de la pena o preventivas especiales, también están destinadas al fracaso, al no poder explicar tampoco el porqué de tal distinción.

27 El artículo 95. ${ }^{\circ}$ establece que el término de la prescripción empieza a correr desde el día en que se hubiere cometido el delito. Mientras que el artículo 141 constituye el título de imputación: secuestro calificado, agravado especialmente por la circunstancia que la privación de libertad de la víctima se haya prolongado más allá de 90 días.

28 Entre otros: Garrido Montt (2009, p. 390). Asimismo, Politoff; Matus; Ramírez (2004, p. 201); Guzmán (2009, p. 67); y Novoa (2005, p. 249 y ss.).

29 La referida sala, denominada también Sala Penal, se encontró integrada por los Ministros Sres. Milton Juica A., Hugo Dolmestch U., Carlos Künsemüller L., Haroldo Brito C., y el abogado integrante Sr. Luis Bates.

30 Sentencia de reemplazo, Corte Suprema, causa rol n. 288-2012, 24 de mayo de 2012. La sentencia se adoptó con mayoría de la sala, con un voto disidente: el voto en contra del Ministro Sr. Hugo Dolmestch, quien estuvo por no dictar sentencia de reemplazo en esta causa en razón de que estuvo por rechazar dicho recurso, manteniendo el fallo de segunda instancia dictado por la Corte de Apelaciones de Concepción, entendiendo la procedencia de la media prescripción. Se previene además que el Ministro Sr. Miltón Juica estuvo por elevar la sanción para los enjuiciados, fijando para cada uno de ellos la pena de diez años de presidio mayor en su grado mínimo, en atención a la naturaleza y gravedad del ilícito aquí investigado y solo acepta en tal caso, por favorecerles una atenuante, no aplicar el grado máximo.

31 Sentencia de casación, Corte Suprema, causa rol n. 288-2012, 24 de mayo de 2012. 


\section{REFERÊNCIAS BIBLIOGRÁFICAS}

AGUILAR CAVALLO, Gonzalo. Crímenes internacionales y la imprescriptibilidad de la acción penal y civil: referencia al caso chileno. Revista Ius et Praxis, año 14, n. 2, Chile, 2008, p. 147-207

AMBOS, Kai; BÖHM, María Laura. La desaparición penal de personas como tipo penal autónomo. Desaparición forzada de personas. Análisis comparado e internacional. VV.AA., Bogotá: Editorial Temis, 2009.

BERGALLI, Roberto. Sistema penal y problema social. Valencia: Editorial Tirant lo Blanch, 2003.

BUSTOS RAMÍREZ, Juan. Manual de Derecho Penal. Parte Especial. Barcelona: Editorial Ariel Derecho, 1986.

CORREA, Sofía, et.al. Historia del siglo XX chileno. Chile: Editorial Sudamericana, 2001.

DÍAZ, D.; MADARIAGA, C. Tercero ausente y familias con detenidos desaparecidos. Cintras, Centro de Salud Mental y Derechos Humanos. Chile, Serie Monografías, n. 10, 1993.

FERNÁNDEZ NEIRA, Karinna; SFERRAZZA TAIBI, Pietro. La aplicación de la prescripción gradual en casos de violaciones de Derechos Humanos. Revista de Estudios Constitucionales, Universidad de Talca, Chile, año 7, n. 1, 2009. FERNÁNDEZ, Karinna. Breve análisis de la jurisprudencia chilena, en relación a las graves violaciones a los derechos humanos cometidos durante la dictadura militar. Revista de Estudios Constitucionales, Talca, Chile, año 8, n. 1, 2010, p. 467-488.

GARRIDO MONTT, Mario. Derecho Penal. Parte Especial. Santiago: Edit. Jurídica de Chile, 2009, t. III. GIL GIL, Alicia. Los crímenes contra la humanidad y el genocidio en el estatuto de la Corte Penal. Instituto

Interamericano de Derechos Humanos. "Atención integral a víctimas de tortura en procesos de litigio. Aportes Psicosociales”. San José, Costa Rica, 2007.

GUZMÁN DÁLBORA, José Luis. Capítulo III: Chile. Ambos, Kai (Coord.): Desaparición forzada de personas. Análisis comparado e internacional. Bogotá: Editorial Temis.

HASSEMER, Winfried. Perspectivas del Derecho Penal del futuro. Traducción Enrique Anarte Borrallo. Revista Penal, Universidad de Huelva, España, 1998, p. 37-41.

HORVITZ, María Inés. Amnistía y prescripción en causas de violación de derechos humanos en Chile. Anuario de Derechos Humanos, Universidad de Chile, 2006, p. 217-225

JAKOBS, Günther; CANCIO MELIA, Manuel. Derecho Penal del enemigo. Madrid: Editorial Thomson/Civitas, 2003. KÜNSEMULLER LOEBENFELDER, Carlos. ¿Tiene futuro el "bueno, viejo, y decente Derecho Penal Liberal"? Nuevas tendencias del Derecho. Santiago: Editorial Lexis Nexis, 2003.

LLEDÓ VASQUEZ, Rodrigo. Derecho Penal Internacional. Chile: Ediciones Congreso, 2000.

MAÑALICH RAFFO, Juan Pablo. El secuestro como delito permanente ante el DL de amnistía. Revista de Estudios de la Justicia, Santiago: Universidad de Chile, año 2004, n. 5.

MUÑNOZ CONDE, Francisco. De las prohibiciones probatorias, al Derecho Procesal Penal del Enemigo. Buenos Aires: Editorial Hammurabi, 2008.

NOVOA MOnREAL. Curso de Derecho Penal Chileno. Parte General, 3. ed. t. II. Santiago: Editorial Jurídica de Chile, 2005.

NOGUEIRA ALCALÁ, Humberto. Informe en Derecho sobre precedentes jurisdiccionales en materia de media prescripción. Revista Ius et Praxis, Talca, Chile, año 14, n. 2, 2008.

PADilla BALLESTEROS, Elías. La memoria y el olvido. Detenidos desaparecidos en Chile. Chile: Ediciones Orígenes, 2010.

POLITOFF, Sergio; MATUS, Jean Pierre; RAmíREZ, María Cecilia. Lecciones de Derecho Penal Chileno. Parte Especial. Editorial Jurídica de Chile, 2004.

POLITOFF, Sergio; TAPIA, Jorge. La concepción bélica de la política. Plural 1. Aproximaciones al tema de la democracia, Rotterdam, n. 1, abr.-jun. 1983, p. 19-35.

QUEZADA CABRERA, Hernan. Comentario a la Sentencia dictada por la Corte Suprema en Caso Pratt. Anuario de Derechos Humanos, Universidad de Chile, n. 7, 2011.

RAFECAS, Daniel Eduardo. La tortura y otras prácticas ilegales a detenidos. Buenos Aires: Editorial Del Puerto, 2010. RAGUÉS IVALLÉS, Ramón. El delito de detención ilegal sin dar razón del paradero de la víctima: dificultades interpretativas de la regulación española. Revista de Estudios de la Justicia, Chile, n. 12, 2010, p. 43-59.

SILVA SÁNCHEZ, Jesús María. La Revolución de la Política criminal, el derecho penal y el proceso penal. Valencia, Editorial Tirant lo Blanch, 2000.

Aproximación al Derecho Penal contemporáneo. Barcelona: Editorial Bosch, 2003.

ZAFFARONI, Eugenio Raúl. En torno de la cuestión penal. Buenos Aires: Editorial B de F, 2005. 
Universidad Central de Chile Lord Cochrane, $n^{\circ} 417$, Torre A, $4^{\circ}$ piso Santiago - RM - Chile igonzalezraucentral.cl

niversidad Central de Chile Lord Cochrane, $n^{\circ} 417$, Torre A, $4^{\circ}$ piso Santiago - RM - Chile samuel.malamudaucentral.cl

Universidad Central de Chile Lord Cochrane, $n^{\circ} 417$, Torre A, $4^{\circ}$ piso

Santiago - RM - Chile mfuentealbamaucentral.cl

Universidad Central de Chile Lord Cochrane, $n^{\circ} 417$, Torre A, $4^{\circ}$ piso Santiago - RM - Chile florenciopardolagmail.com

\section{Isabel González Ramírez}

Abogada
Magíster en Derecho Penal
Egresada del Doctorado en Derecho de la Universidad
Católica de Valparaíso
Directora del Centro de Mediación y Arbitraje,
Universidad Central de Chile

\section{Samuel Malamud Herrera}

Abogado

Máster en Derecho Penal, Universidad de Sevilla Cursando Doctorado en Derecho Penal, Universidad de BUENOS AIRES ACAdÉmico E InVEstigador, Universidad Central DE Chile

\section{María Soledad Fuentealba Martínez}

PSICÓlOgA

Magíster en Mediación, Universidad Central de Chile Cursando Doctorado en Derecho Penal, Universidad de BUENOS AIRES ACADÉMICA E INVESTIgAdORA, UNIVERSIDAd CENTRAL

\section{Florencio Pardo Montenegro}

ABOGADO

Magíster en Derecho Penal, Universidad de Chile Cursando Doctorado en Derecho Penal, Universidad de BUENOS AIRES ACAdÉMICo, UnIVERSIDAd ARCIS 